\title{
Human Adipose Derived Stem Cells Induced Cell Apoptosis and $S$ Phase Arrest in Bladder Tumor
}

\author{
Xi Yu, ${ }^{1,2}$ Boxing Su, ${ }^{1,2}$ Peng Ge, ${ }^{1,2}$ Zicheng Wang, ${ }^{1,2}$ Sen Li, ${ }^{3}$ Bingwei Huang, \\ Yanqing Gong, ${ }^{1,2}$ and Jian $\operatorname{Lin}^{1,2}$ \\ ${ }^{1}$ National Urological Cancer Center, Beijing 100034, China \\ ${ }^{2}$ Department of Urology, Peking University First Hospital and the Institute of Urology, Peking University, Beijing 100034, China \\ ${ }^{3}$ Beijing Shunyi District Hospital, Beijing 101300, China \\ ${ }^{4}$ Qinzhou First People's Hospital, Qinzhou 535000, China
}

Correspondence should be addressed to Jian Lin; linjianbj@163.com

Received 15 October 2014; Revised 24 December 2014; Accepted 7 January 2015

Academic Editor: Boon Chin Heng

Copyright (C) $2015 \mathrm{Xi} \mathrm{Yu}$ et al. This is an open access article distributed under the Creative Commons Attribution License, which permits unrestricted use, distribution, and reproduction in any medium, provided the original work is properly cited.

The aim of this study was to determine the effect of human adipose derived stem cells (ADSCs) on the viability and apoptosis of human bladder cancer cells. EJ and T24 cells were cocultured with ADSCs or cultured with conditioned medium of ADSCs (ADSC-CM), respectively. The cell counting and colony formation assay showed ADSCs inhibited the proliferation of EJ and T24 cells. Cell viability assessment revealed that the secretions of ADSCs, in the form of conditioned medium, were able to decrease cancer cell viability. Wound-healing assay suggested ADSC-CM suppressed migration of T24 and EJ cells. Moreover, the results of the flow cytometry indicated that ADSC-CM was capable of inducing apoptosis of T24 cells and inducing S phase cell cycle arrest. Western blot revealed ADSC-CM increased the expression of cleaved caspase- 3 and cleaved PARP, indicating that ADSC-CM induced apoptosis in a caspase-dependent way. PTEN/PI3K/Akt pathway and Bcl-2 family proteins were involved in the mechanism of this reaction. Our study indicated that ADSCs may provide a promising and practicable manner for bladder tumor therapy.

\section{Introduction}

Bladder tumor (BT) is the 11th most common cancer and the 14th leading cause of cancer deaths worldwide. It is estimated that about 386,300 people are diagnosed with BT and 150,200 died of this disease in 2012 [1]. The morbidity of male is more than 3 times higher than female and this disparity is more obvious in developed countries. So far, well established risk factors for BT include tobacco use, infections with Schistosoma haematobium, and occupational exposure to aromatic amines, chronic irritation, and polycyclic aromatic hydrocarbons $[2,3]$. Most non-muscle-invasive BT is generally treated by transurethral resection of bladder tumor (TUR-BT), followed by adjuvant intravesical therapy. Muscleinvasive cases prefer radical cystectomy and lymphadenectomy followed by adjuvant chemotherapy or radiotherapy. The treatment scheme of BT is expensive and brought huge economic burden to patients. Are there other means that would improve prognosis?

Mesenchymal stem cells (MSCs) have received much attention in recent years owing to their capacity to differentiate into many other cell types including bone, cartilage, stroma, adipose, muscle, tendon, and connective tissue $[4,5]$. Recently, more and more studies have found out that MSCs can secrete various cytokines and chemokines which affect the proliferation of tumor cells. MSCs have been proved to increase the growth of colon (KM12SM) [6], prostate [7], lung, or glioma (H460 or U87MG) [8] cancer cells, while inhibiting the growth of pancreatic cancer cells [9], Kaposi sarcoma [10], hepatoma (H22), and non-Hodgkin's lymphoma (SKW6.4 and BJAB) [11]. But it is difficult to obtain MSCs. Adipose tissue, containing a stroma which is easily isolated, is derived from the embryonic mesenchyme. Many studies have identified a putative stem cell within the 
adipose stromal compartment termed ADSCs which share the same characteristic with MSCs and can differentiate toward the adipogenic, osteogenic, chondrogenic, and myogenic lineages [12].

There are debates about the ability of ADSCs to support or suppress tumor cell proliferation [8,13-15]. Unfortunately, there are few reports about BT. The purpose of this investigation was to investigate the effects of ADSCs on the growth of bladder cancer cells and to explore the underlying mechanisms. In this paper, we used direct and indirect coculture to detect whether ADSCs may stimulate or inhibit cancer cell growth. If the ADSCs exert an inhibitory effect on cancer cells, it may potentially be used to treat currently incurable BT patients.

\section{Materials and Methods}

2.1. Ethics Statement. Human adipose tissues were obtained from subcutaneous fat of patients who underwent radical nephrectomy at Department of Urology, Peking University First Hospital. All patients signed informed consent. This study was approved by Human Research Ethics Committee of Peking University First Hospital (approval ID: 2014[835]).

2.2. Chemicals and Reagents. Collagenase I, dexamethasone, ascorbate-2-phosphate, pantothenic acid, and insulintransferrin-sodium selenite supplement were purchased from Sigma Aldrich (St. Quentin Fallavier, France). Trypsin, Dulbecco's modified Eagle's medium (DMEM), penicillin, streptomycin, and phosphate buffered saline (PBS) were provided by Hyclone (Cergy-Pontoise, France). Fetal bovine serum (FBS) for ADSCs was purchased from Gibico (Paris, France). LY294002 was purchased from Cell Signaling Technology (CST, Beverly, MA, USA).

2.3. ADSCs Preparation and Culture. The adipose tissues were washed carefully with sterile PBS to remove debris and red blood cells. Then we cut them into tiny pieces with scissors. The pieces were treated with $0.1 \%$ collagenase I in $\mathrm{DMEM}$ at $37^{\circ} \mathrm{C}$ for $60 \mathrm{~min}$ with gentle agitation. Then the mixture was centrifuged for $10 \mathrm{~min}$ at $1000 \mathrm{r} / \mathrm{min}$. The cellular precipitate was resuspended in DMEM with 10\% FBS and then filtered through a $100 \mathrm{~m}$ mesh filter to remove debris. The filtrate was plated onto cell culture plates and maintained in an incubator at $37^{\circ} \mathrm{C}$ with $5 \% \mathrm{CO}_{2}$. The medium was changed every two days. Cells at passages 3 6 were used for experiments.

2.4. Adipogenic Differentiation and Oil Red Staining. Cells were seeded in expansion medium at a density of $2 \times 10^{4} / \mathrm{cm}^{2}$. When reaching 90\% confluence, adipogenesis was induced by adipogenic medium (AM): DMEM supplemented with $10 \%$ FBS, $0.5 \mathrm{mM}$ isobutyl-methylxanthine (IBMX), $1 \mathrm{mM}$ dexamethasone, $10 \mathrm{mM}$ insulin, $200 \mathrm{mM}$ indomethacin, and $1 \%$ antibiotic/antimycotic for 2 weeks $[12,16]$. Prior to staining, the cells were fixed in $4 \%$ formaldehyde for $60 \mathrm{~min}$ at room temperature and washed with $70 \%$ ethanol. The cells were incubated in $2 \%(\mathrm{wt} / \mathrm{vol})$ Oil Red $\mathrm{O}$ reagent for $5 \mathrm{~min}$ at room temperature. Excess stain was removed by washing with $70 \%$ ethanol followed by several changes of distilled water. The cells were then counterstained for $2 \mathrm{~min}$ with hematoxylin.

2.5. Osteogenic Differentiation and Von Kossa Staining. Cells were seeded in expansion medium at a density of $2 \times 10^{4} / \mathrm{cm}^{2}$. When reaching $90 \%$ confluence, they were induced in the following osteogenic medium (OM) for 2 weeks: DMEM supplemented with $10 \% \mathrm{FBS}, 0.1 \mathrm{mM}$ dexamethasone, $50 \mathrm{mM}$ ascorbate-2-phosphate, $10 \mathrm{mM}$ b-glycerophosphate, and $1 \%$ antibiotic/antimycotic $[12,16]$. For Von Kossa staining, cells were incubated in OM for 4 weeks and then fixed with $4 \%$ paraformaldehyde for $60 \mathrm{~min}$ at room temperature. The cells were rinsed with distilled water and then overlaid with a $1 \%$ (wt/vol) silver nitrate solution for $30 \mathrm{~min}$ in the absence of light. The cells were washed with distilled water several times and developed under UV light for $60 \mathrm{~min}$. In the end, the cells were counterstained with $0.1 \%$ eosin in ethanol.

2.6. Cell Lines. Bladder cancer cell lines studied included EJ and $\mathrm{T} 24$. These cell lines were cultured at $37^{\circ} \mathrm{C}$ in $5 \% \mathrm{CO}_{2}$ and routinely maintained in DMEM supplemented with 10\% FBS, $1 \%$ penicillin $\mathrm{G}$, and $1 \%$ streptomycin.

2.7. Cell Number Assessment. Before serum starvation for 16 hours, EJ and T24 cells were cultured in complete DMEM in 6-well plates for $24 \mathrm{~h}$. Experimental cells were cocultured with ADSCs in a transwell membrane with $1.0 \mu \mathrm{m}$ holes for another 48 hours. Control cells were cultured with cancer cells. Cell growth was measured by cell counting using a cell counter model (Muse).

2.8. Cell Viability Assay. EJ and T24 cells were cultured in complete medium in 96-well plates for $24 \mathrm{~h}$, before serum starvation for 16 hours. Experimental cells were cultured in ADSC-CM for 48 hours in triplicate. Control cells were cultured in cancer cells conditioned medium. Cell viability was then measured by MTS assay, according to the manufacturer recommendations (CellTiter96 AQueous Assay, Promega, France). To draw the cell growth curve, cells were cultured for $120 \mathrm{~h}$ and measured by MTS assay every $24 \mathrm{~h}$.

2.9. Flow Cytometry. To measure apoptosis, an FITC annexin $\mathrm{V}$ apoptosis detection kit (BD PharMingen, 556547) was used according to the manufacturer's instructions. The cells were stained with annexin V/PI and detected with flow cytometry. All flow cytometry data were analyzed with FlowJO software.

To measure cell cycle, a DNA content quantitation assay (cell cycle) kit (KeyGEN, KGA512) was used according to the manufacturer's instructions. The cells were stained with PI and detected with flow cytometry. All flow cytometry data were analyzed with ModFit software.

2.10. Colony Formation Assay. Digest the cells at logarithmic growth phase and dilute the suspension at multiple grades. For each cell group, 400 cells were seeded onto the plate 
containing $5 \mathrm{~mL} 37^{\circ} \mathrm{C}$ prewarmed broth dish and gently rotated to be evenly dispersed and then incubated in $37^{\circ} \mathrm{C}$ and $5 \% \mathrm{CO}_{2}$ humidified incubator for $2 \sim 3$ weeks. When visible cloning appeared in the well, the culture was terminated. Discard the supernatant carefully and dip the dish two times with PBS. Add $5 \mathrm{~mL} \mathrm{4 \%}$ paraformaldehyde to fix cells for 15 minutes. Remove the fixative and add appropriate amount of crystal violet dye for 10 to 30 minutes; then wash away the stain slowly with water and air drying. Clones greater than 10 cells were counted with the microscope (low magnification).

2.11. Wound-Healing Assay. Cells were seeded in 6-well plates and cultured at concentrations to yield 90 95\%. Cells were then scratched with a $200 \mu \mathrm{L}$ pipette tip and washed three times with PBS. Medium containing $1 \%$ FBS and ADSC-CM were added to the wells. Wound areas were examined after $0 \mathrm{~h}, 12 \mathrm{~h}$, and $24 \mathrm{~h}$ of incubation under an OLYMPUS inverted microscope connected to a DXM1200 digital camera (Nikon, Tokyo, Japan).

2.12. Western Blotting. Whole-cell lysates were prepared in lysis buffer (50 mM Tris-HCl, pH 7.4, $150 \mathrm{mM} \mathrm{NaCl}, 1 \mathrm{mM}$ EDTA, $1 \%$ NP-40, and $0.1 \%$ sodium dodecyl sulfate), quantified, and loaded onto SDS-PAGE. After electrophoresis, proteins in the gel were transferred to a nitrocellulose membrane and incubated with primary antibodies at $4^{\circ} \mathrm{C}$ overnight. The membrane was incubated with HRP-conjugated secondary antibodies for $1 \mathrm{~h}$ at room temperature and then washed with TBST. The antibody complexes in the immunoblots were detected by chemiluminescence using an HRP substrate (Millipore, Bedford, MA, USA; WBKLS0100) and visualized using a G:BOX Chemi Gel Documentation System (Syngene, Frederick, MD, USA).

2.13. Statistical Analysis. All data was analyzed by SPSS software (version 18.0). The results were expressed as the mean \pm SD. Statistical analyses were performed using Student's $t$-test. The significance level was set at 0.05 .

\section{Results}

3.1. Characteristics of Adipose Derived Stem Cells. After 3 days of growing from the initial plating, the fibroblastoid cells formed a monolayer. Then we replaced the medium every two days. The fibroblastoid cells were termed ADSCs. Cells exhibited homogeneous shapes when it came to the second or third generation (Figures 1(a) and 1(b)). To characterize the ADSCs population, CD marker profile was examined by flow cytometry. As reported [12, 16-18], ADSCs expressed CD44, CD73, CD90, and CD105. In contrast, no expression of CD34 and CD45 was observed in either of the cultures (Figure 1(c)). And ADSCs are able to differentiate into adipogenic, osteogenic lineages (Figure $1(\mathrm{~d})$ ).

3.2. ADSCs Inhibited EJ and T24 Cells Proliferation and Viability. To determine effect of ADSCs on EJ cells and T24 cells growth in vitro, we evaluated the viability and progression of cancer cells exposed to ADSCs. The ADSCs were used for coculture with cancer cells after three passages in the presence of $1: 1$ ratio of cancer cells (Figure 2(a)). Cell proliferation rate decreased significantly in the experimental group when compared with the control group after $48 \mathrm{~h}$ (Figures 2(b) and 2(c)).

The result from the indirect cell-to-cell contact in our experiment prompted us to infer that maybe some soluble factors were released from ADSCs and could have an effect on cancer cells viability. In fact, soluble factors had been demonstrated to regulate the immunosuppressive effect of human ADSCs previously [19]. As shown in Figures 2(d) and 2(e), ADSC-CM could inhibit the viability of EJ and T24 cells, while as a control conditioned medium from cancer cells alone did not significantly impair cancer cells viability.

We also determined the proliferation of EJ and T24 cells treated with ADSC-CM using colony formation assay. We found a significant reduction of colony formation number in treated group compared with control group (Figures 2(f) and $2(\mathrm{~g}))$.

3.3. ADSC-CM Suppressed Migration of EJ and T24 Cells. To evaluate the effect of ADSC-CM on the motility of cancer cells, we performed a wound-healing assay. After incubating for $24 \mathrm{~h}$, we found the migrating cells in the treated groups were significantly reduced compared to control groups (Figures 3(a), 3(b), 3(c), and 3(d)).

3.4. Induction of Apoptosis of Cancer Cells by ADSC-CM. As mentioned above, ADSC-CM inhibited cancer cell growth; then we speculated whether ADSC-CM also induced cell apoptosis. With a treatment of $48 \mathrm{~h}$, we observed increased percentage of early apoptotic cells as well as the late apoptotic cells in treated group (Figures 4(a), 4(b), and 4(c)). Consistent with the MTS assay, the results revealed that ADSC-CM induced cellular apoptosis.

3.5. ADSC-CM Induces S Phase Cell Cycle Arrest. Treatment of T24 cells with ADSC-CM resulted in inhibition of cells growth and induced apoptosis, so we considered the possibility that it may involve an arrest of cells at a specific check point in the cell cycle. In consistence with our hypothesis, compared with the control group, ADSC-CM treatment leaded to an appreciable arrest in S phase of the cell cycle. Cell cycle analysis showed that the $S$ phase population of the control cells was $32.85 \%$ (Figure 5(a)) and the percentage of cells in S phase increased to $42.36 \%$ (Figure 5(b)) after $48 \mathrm{~h}$ treatment. This increase in $\mathrm{S}$ phase cell population was accompanied with a decrease of cell number in G1 phase.

ADSC-CM induced apoptosis was mediated by $\mathrm{Bcl}-2$ family modulation and caspase activation.

To further understand this cell specific apoptotic effect of ADSC-CM on cancer cells, we also analyzed the activation of caspases and the levels of Bcl-2 family proteins. As we know, the change of the ratio of antiapoptotic protein versus proapoptotic proteins of Bcl-2 family proteins would activate the mitochondrial apoptotic pathway. Our data suggested that Bcl-2 expression was downregulated by ADSC$\mathrm{CM}$ whereas the level of Bax expression was upregulated 


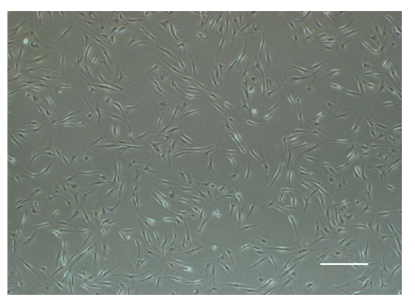

(a)
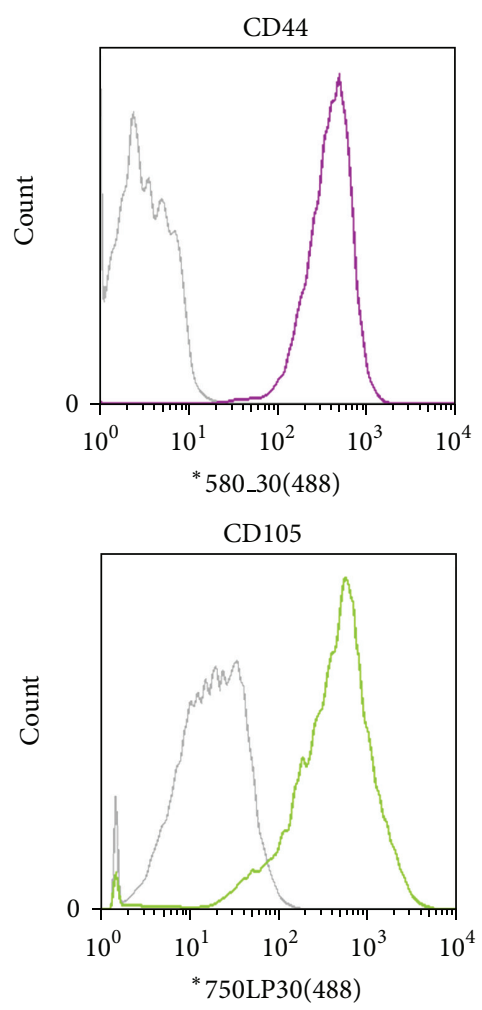

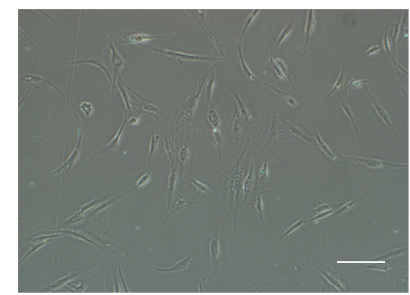

(b)
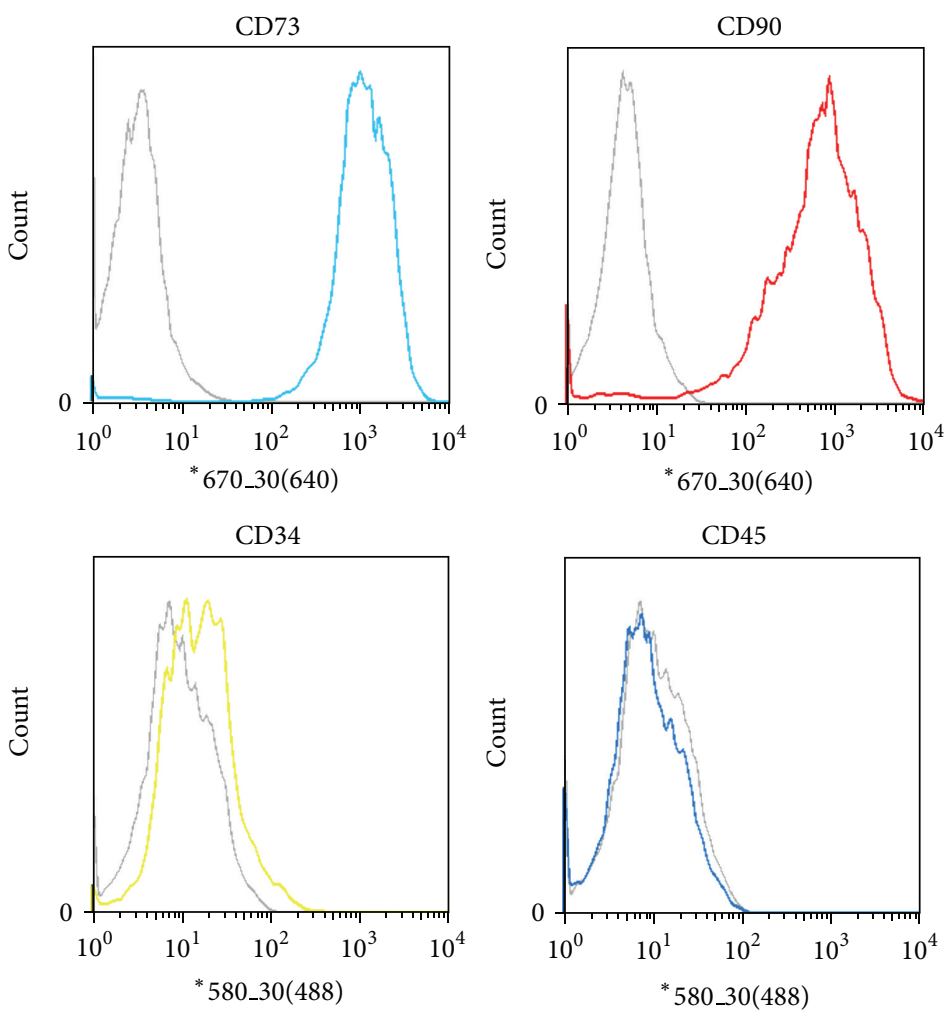

(c)

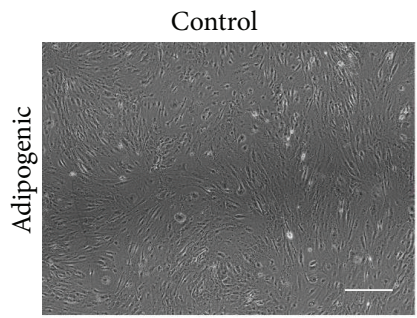

Differentiated

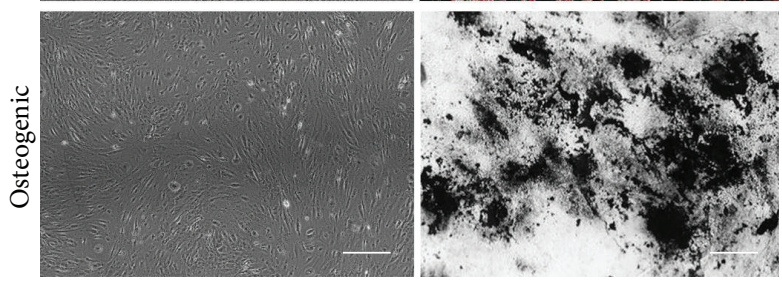

(d)

FIGURE 1: Characterization of ADSCs. ADSCs exhibited a flattened fibroblast-like morphology. Observed under a microscope of 40x (a) and 100x (b). Immunophenotype of ADSCs (c). ADSCs were stained with antibodies against the indicated antigens and analyzed by flow cytometry. Representative histograms are shown as colored lines, and the respective isotype controls are shown as a gray line. ADSCs were positive for CD44, CD73, CD90, and CD105 and negative for CD34 and CD45. ADSCs are able to differentiate into adipogenic and osteogenic lineages, as shown by staining with Oil Red O and Von Kossa, respectively (d). Undifferentiated (control) ADSCs are not marked with the stains. Scale bars, $100 \mu \mathrm{m}((\mathrm{a})$, (d)) and $50 \mu \mathrm{m}$ (b). 


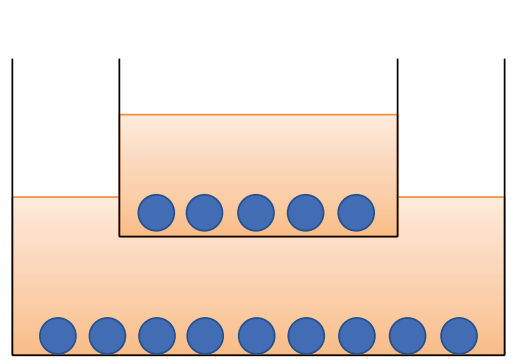

(a)

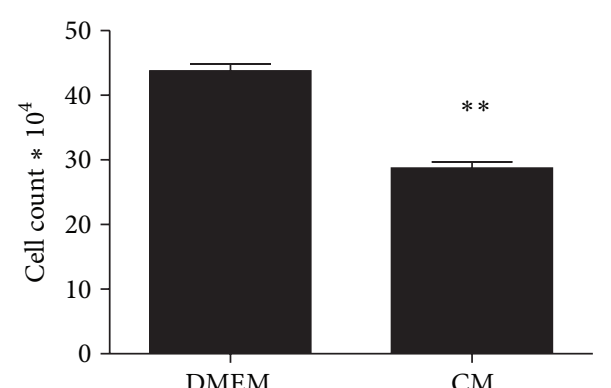

(b)

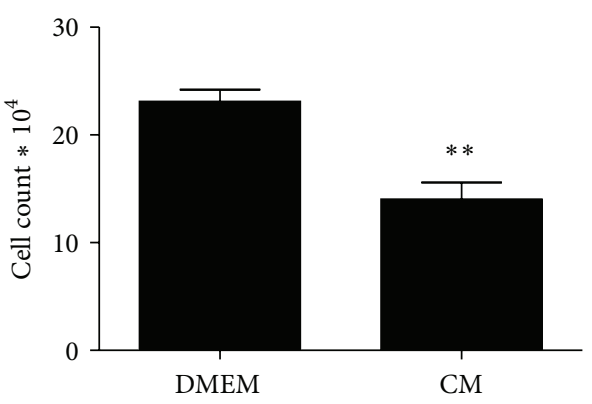

(c)

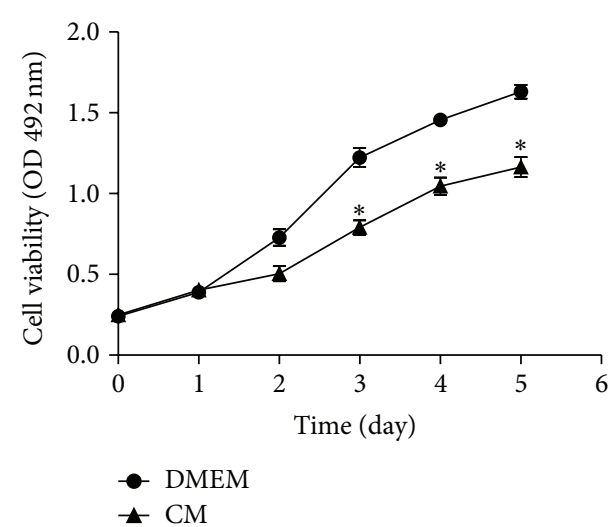

(d)

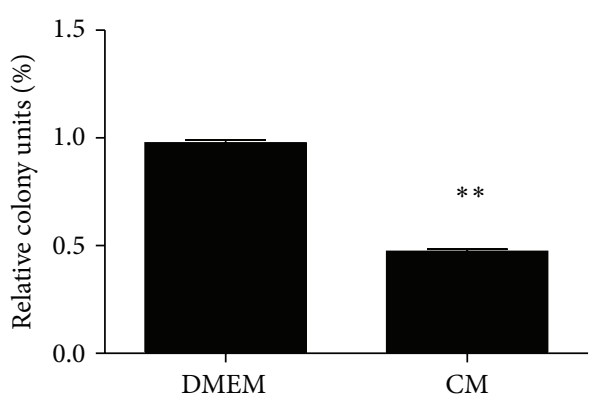

(f)

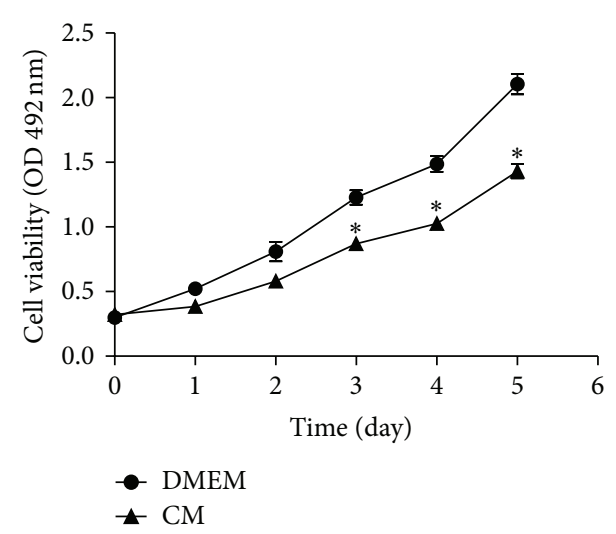

(e)

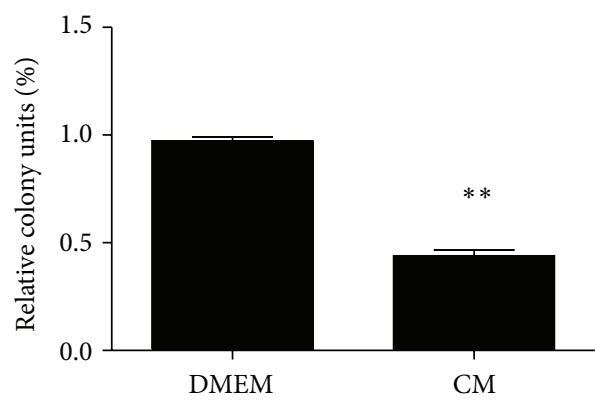

(g)

FIGURE 2: The effect of ADSCs on the growth of human bladder cancer cells. (a) ADSCs and bladder cancer cells were cultured in a transwell membrane with $1.0 \mu \mathrm{m}$ holes, the upside was ADSCs, and EJ or T24 cells were below. The number of EJ (b) and T24 (c) cell lines was less in the treated group than the control group. Data are shown as the means $\pm \mathrm{SD}\left({ }^{* *} P<0.01\right.$ versus control). Three independent experiments were conducted. The effect of ADSC-CM on the viability of EJ (d) or T24 (e) cells. EJ and T24 cells viability was inhibited. Data shown were the mean $\pm \mathrm{SD}$ of three independent experiments $\left({ }^{*} P<0.05\right.$ versus control). Treatment of ADSC-CM led to a significant reduction in the number of EJ (f) or T24 (g) colony formation units relative to control cells $\left({ }^{* *} P<0.01\right.$ versus control).

compared to the control group. ADSC-CM treatment also caused an increase in the levels of cleaved caspase- 3 and cleaved PARP which were indicative of an induction of apoptosis (Figure 6).

3.6. ADSC-CM Modulated Akt Pathway within Cancer Cells. Recently, many studies showed PI3K-Akt can inhibit apoptosis and promote cell survival via multiple pathways [20, 21]. To determine whether ADSC-CM induced apoptosis by this pathway, we investigated the expression of p-Akt (phosphorylation of Akt) and total Akt after treatment with
ADSC-CM for $48 \mathrm{~h}$. Western blot analysis showed expression of p-Akt was decreased while no significant difference existed in total Akt. These results indicated that PI3K/Akt pathway played an important role in the ADSC-CM induced apoptosis in bladder cancer cells. To deeply investigate the modulation of ADSC-CM on PI3K/Akt pathway, we suppressed Akt activity with LY294002, a PI3K specific inhibitor. Cell viability was assessed with the MTS assay and protein expressions were analyzed by Western blotting. The results indicated that LY294002 enhanced ADSC-CM induced expression changing of Bax, Bcl-2, and p-PTEN (Figure 7(a)). As shown 

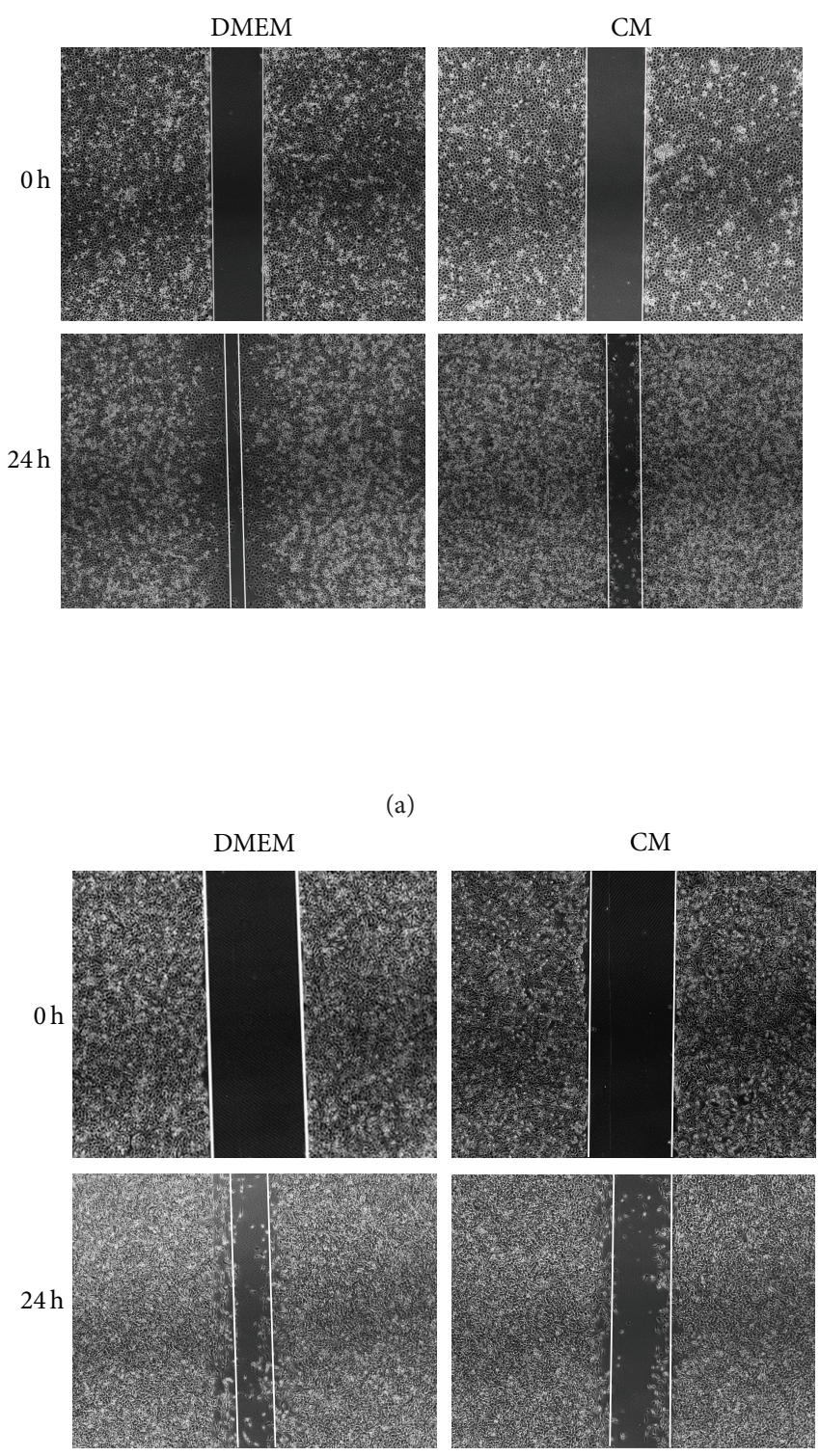

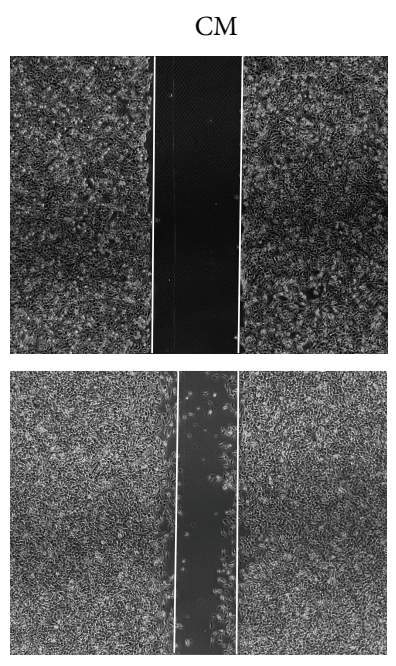

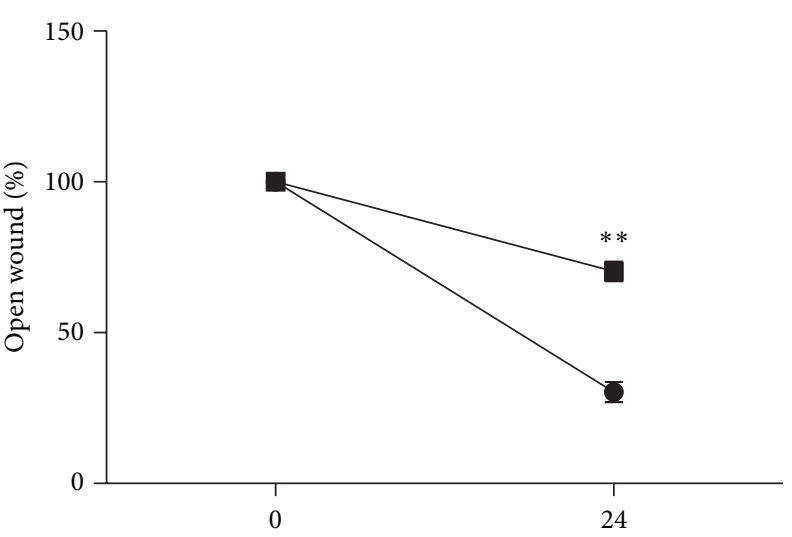

(h)

(b)

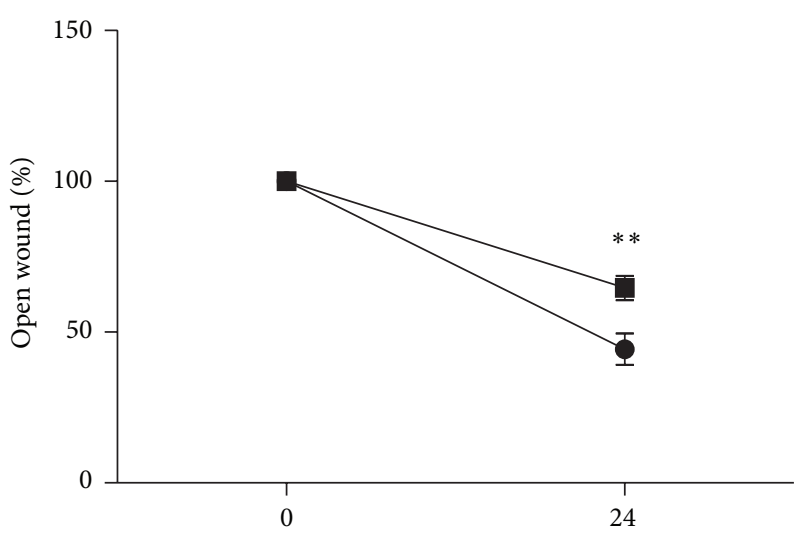

(h)

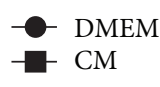

(c)

(d)

FIGURE 3: ADSC-CM suppresses migration of EJ and T24 cells. Representative images of wound gaps in ADSC-CM treated EJ (a) or T24 (c) cells and DMEM treated cells at different time points. Original magnification: $\times 40$. Pictures captured at 0 or $24 \mathrm{~h}$ represented width of open wound compared with $0 \mathrm{~h}\left({ }^{* *} P<0.01\right)$.

(Figure 7(b)), ADSC-CM combined with LY294002 treatment inhibited cancer cells growth more significantly than ADSC-CM alone. This implied the PTEN/PI3K/Akt signaling pathway played an important role in ADSCs' antitumor effects on bladder cancer cells.

\section{Discussion}

Recently, using ADSCs as a vehicle in tumor gene therapy had been proposed [22-25]. ADSCs' antitumor effect had been described in many studies. The mechanisms referred to the fact that ADSCs might possess several characteristics which made them be recruited to tumor and then affect cancer cells viability. The interactions between ADSCs and cancer cells, especially the secreted soluble factors, played an important role. These cytokines secreted by ADSCs (such as DKK-1, SDF-1, TGF- $\beta$, and RANTES), prostaglandins (such as PGE2, PGI2, and PGJ2), or interleukins (such as IL6, IL8, GSF, and IL11) were known to exert an antiproliferative or proapoptotic effect [26-30]. 


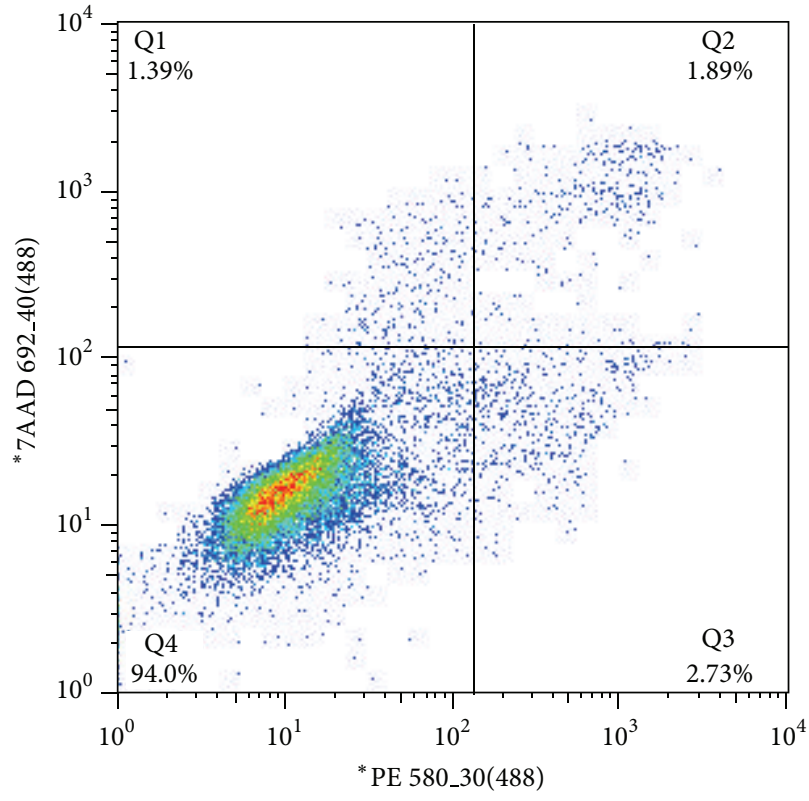

(a)

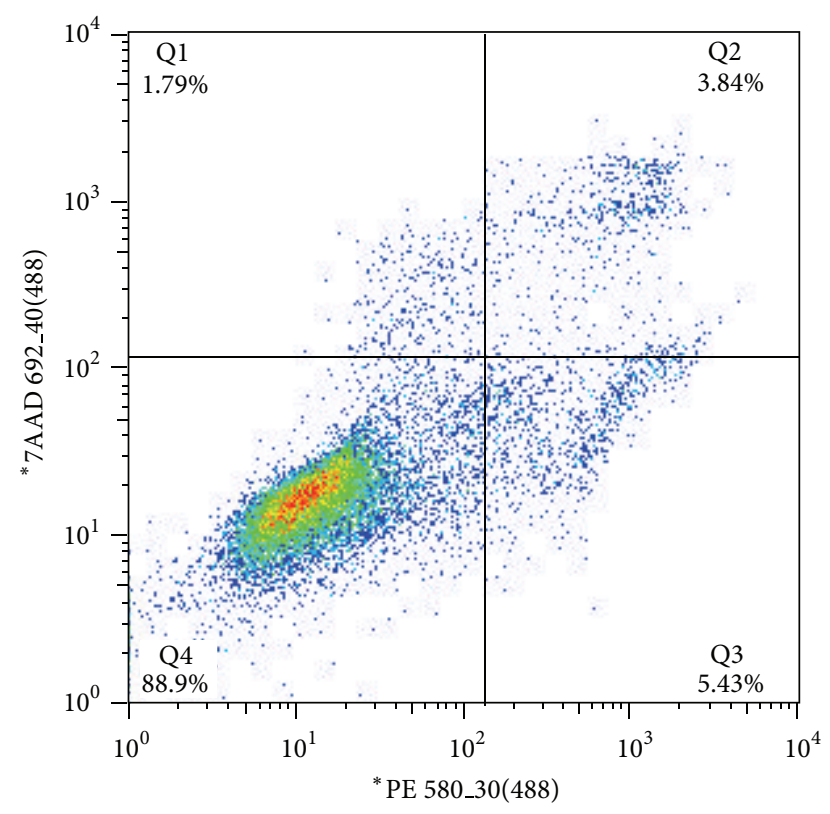

(b)

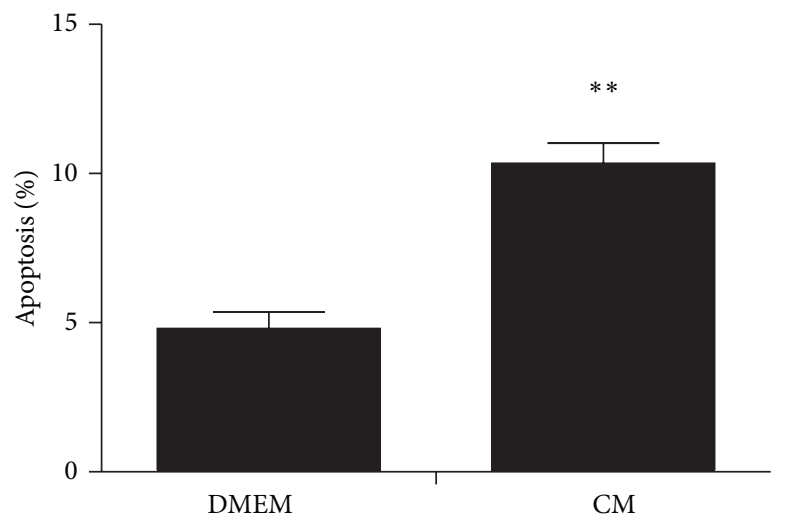

(c)

FIgURE 4: ADSC-CM treatment induces apoptosis in T24 cell line. Cells were double-stained with annexin V and PI and analyzed by flow cytometry. The gate setting distinguished between living (bottom left), necrotic (top left), early apoptotic (bottom right), and late apoptotic (top right) cells. T24 cells were treated with DMEM (a) as a control. Apoptosis was induced by ADSC-CM treatment (b). The apoptosis of T24 cells (c) was increased in the test group more than the control group from three independent experiments $\left({ }^{* *} P<0.01\right.$ versus control).

Our findings demonstrated the ability of ADSCs sampled from different donors to inhibit cancer cell phenotypes in two experimental systems. First, the coculture experiments reveled that ADSCs had a significant antiproliferative effect on cancer cells. Then, in order to determine whether some secreted factors were involved in this inhibition, we treated cancer cells with conditioned media of ADSCs. We found the growth of cancer cells was inhibited and the rate of apoptosis was higher in these experimental groups. Apoptosis and cell cycle arrest represented two different mechanisms involved in the induction of cell death. It was established that loss of cell cycle checkpoints was a hallmark of cancer cells, which would lead to oncogenic transformation and abnormal proliferation [31]. In our experiment, cell cycle was arrested at $\mathrm{S}$ phase without progressing into G2-M phase. The data suggested that ADSC-CM treatment made the cancer cells unable to accomplish normal mitosis and then undergo apoptotic death. This result was consistent with observations of our previous MTS assessment. Blocking of S phase of T24 cells cell cycle had already been reported by many articles and it may be associated with downregulation of Bcl-2 [32-35].

Finally, we characterized some of the molecular events including Bax, Bcl-2, cleaved caspase-3, and cleaved PARP which may be associated with soluble factors from ADSC$\mathrm{CM}$. The Bcl-2 protein family consisted of antiapoptotic protein (Bcl-2) and proapoptotic proteins (Bax and Bad) that regulated cytochrome c release, mitochondrial outer membrane integrity, and caspase activation leading to apoptosis. 


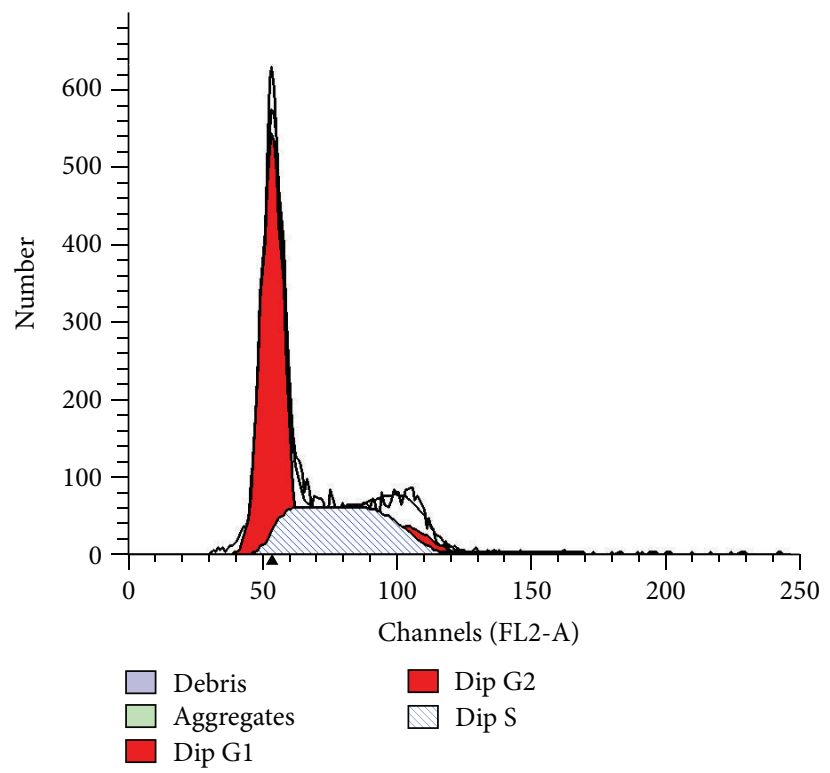

(a)

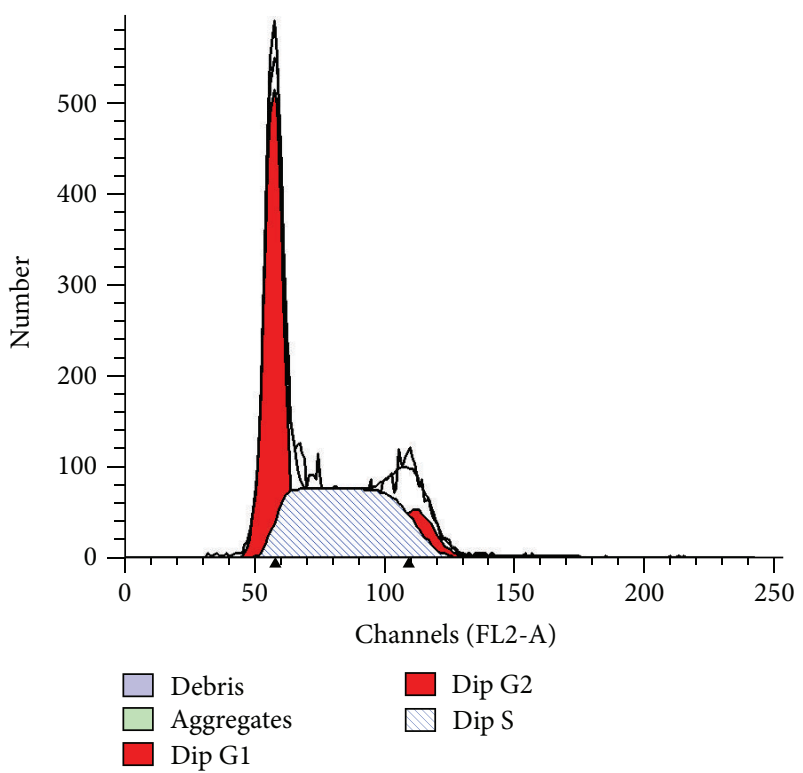

(b)

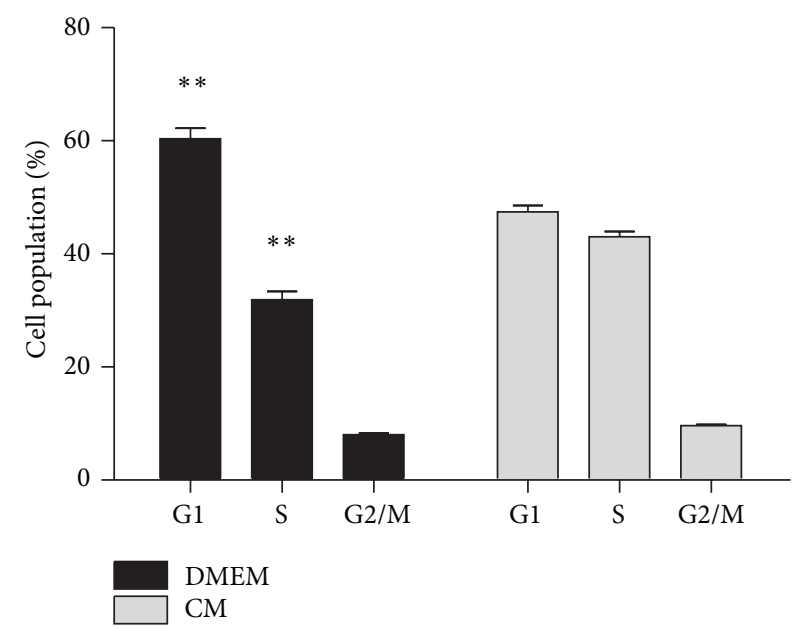

(c)

FIGURE 5: Cell cycle analysis of T24 bladder cancer cells. Cells were treated with DMEM (a) or ADSC-CM (b) for $48 \mathrm{~h}$ and then stained with propidium iodide. The DNA content was analyzed by flow cytometry. G1, S, and G2/M indicate cell cycle phase. (c) It shows an obvious $S$ phase arrest with a concomitant decrease of cell number in G1 phase of the cell cycle. The percent of $S$ phase was quantified from three independent experiments $\left({ }^{* *} P<0.01\right.$ versus control).

Breaking the balance of Bcl-2 family members would result in proapoptotic effects in which caspase-3 is activated and executes the apoptotic program [36]. The present study indicated that ADSC-CM treatment downregulated the antiapoptotic protein $\mathrm{Bcl}-2$ while upregulating the proapoptotic protein Bax. The changes could induce cytochrome $\mathrm{c}$ release from mitochondria and then cytosolic cytochrome $\mathrm{c}$ binding to Apaf-1 and activation of caspase-3 and PARP [37]. In our research, we confirmed that ADSC-CM could activate caspase- 3 and lead to PARP cleavage.

PI3K/Akt was one of the most effective antiapoptotic survival pathways and also an important cell survival factor in several types of cancer, including bladder cancer. There have been studies demonstrating that expression of $\mathrm{Bcl}-2$ increased at the time when PI3K/Akt pathway was activated [38]. Meanwhile, Akt also inhibited apoptosis through mitochondrial pathways [39]. PTEN, a potent tumor suppressor which could inhibit PI3K/Akt signaling and reduced PTEN protein expression, was commonly found in bladder cancer [40-42]. So we considered that Akt might be involved in this process and ADSC-CM might inhibit PI3K/Akt signaling by upregulating p-PTEN. Consistent with our hypothesis, our data showed there was a significant inhibition in p-PTEN and phosphorylated Akt (at S473). Here we proved ADSC-CM 


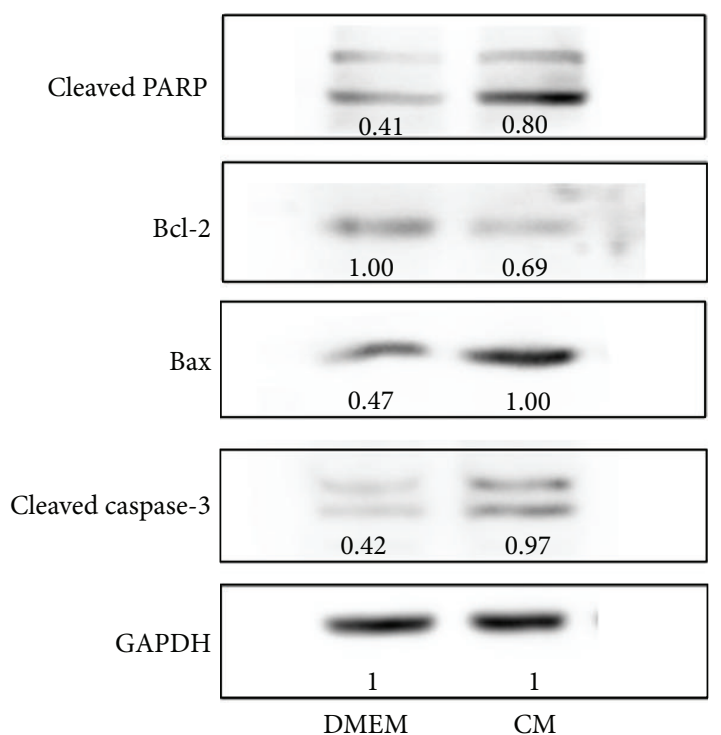

(a)

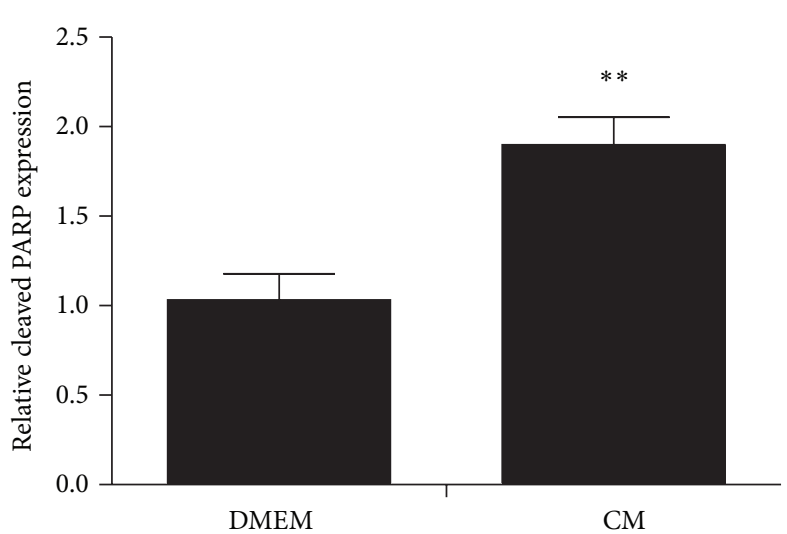

(b)

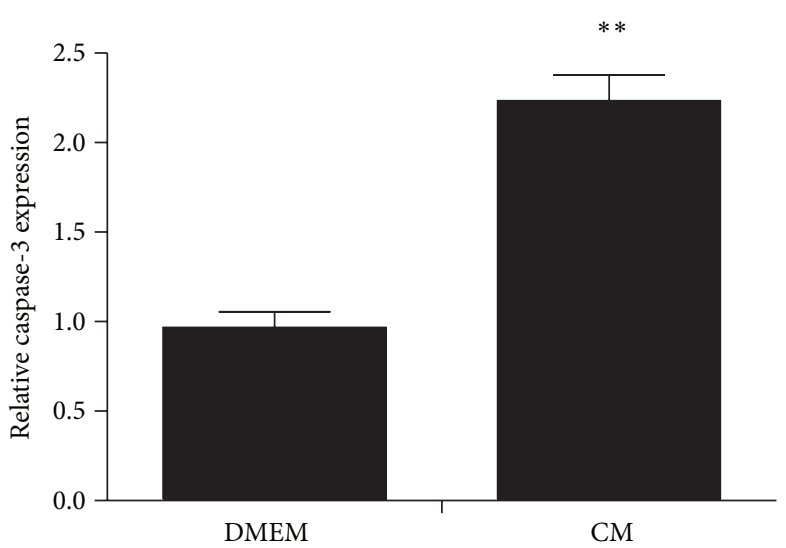

(c)

FIGURE 6: After treatment with ADSC-CM, the expression of antiapoptotic gene products Bcl-2 was inhibited but the expression of apoptotic gene product Bax was upregulated (a). Cleaved PARP (b) and Caspase-3 (c) showed a higher expression in the ADSC-CM treated group. Relative gray values of each protein band were marked under the bands which were measured by Image J software. Data presented are the mean $\pm \mathrm{SD}$ of three independent experiments $\left({ }^{*} \mathrm{P}<0.05\right)$.

treatment induced T24 cells apoptosis via PTEN/PI3K/Akt pathway and Bcl-2 family. Moreover, we observed cancer cells treated with a combination of ADSC-CM and LY294002 (a PI3K inhibitor) showed an increased growth inhibition compared with ADSC-CM alone. This implied that ADSC$\mathrm{CM}$ could help counter resistance when used together with existing cancer therapies.

\section{Conclusion}

For the first time, we have provided the evidence to prove that ADSCs could obviously inhibit the proliferation of bladder cancer cells through apoptosis. The antiproliferative effect of ADSCs on bladder cancer cells appears to be mediated by the secretion of soluble factors which are involved in the PTEN/PI3K/Akt signaling pathway. Since ADSCs can be easily obtained as a stem cell source without ethical concerns and can be amplified quickly, ADSCs may provide a promising and practicable manner for bladder cancer therapy. However, further in vivo studies are needed to provide a more comprehensive insight into its antitumor effect.

\section{Conflict of Interests}

The authors declare that there is no conflict of interests regarding the publication of this paper.

\section{Acknowledgments}

This study was supported by grants from the Wu Jieping Medical Foundation (no. WJP-LC-12036). The authors also 


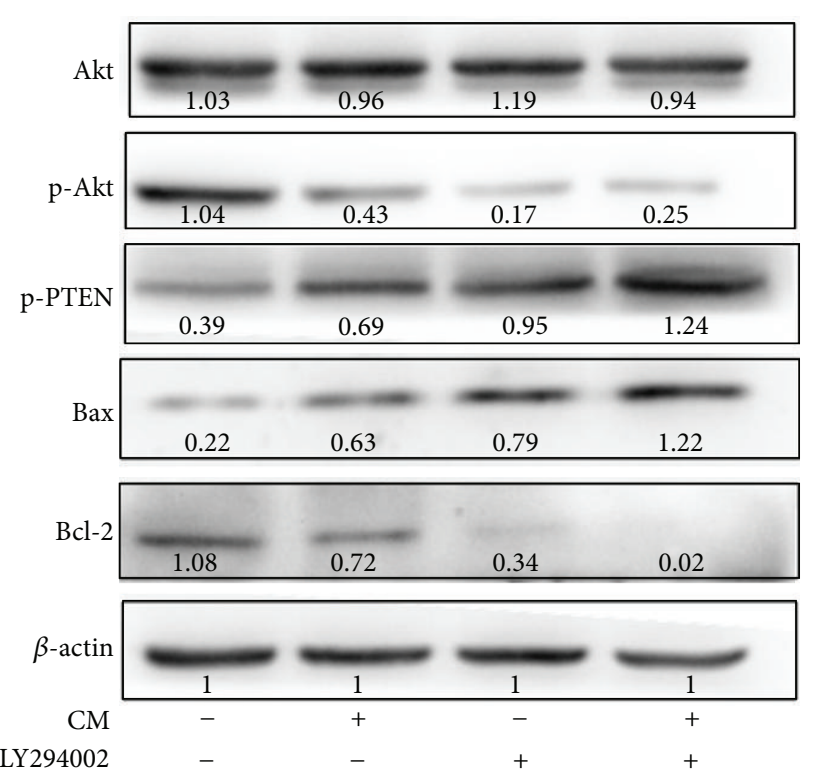

(a)

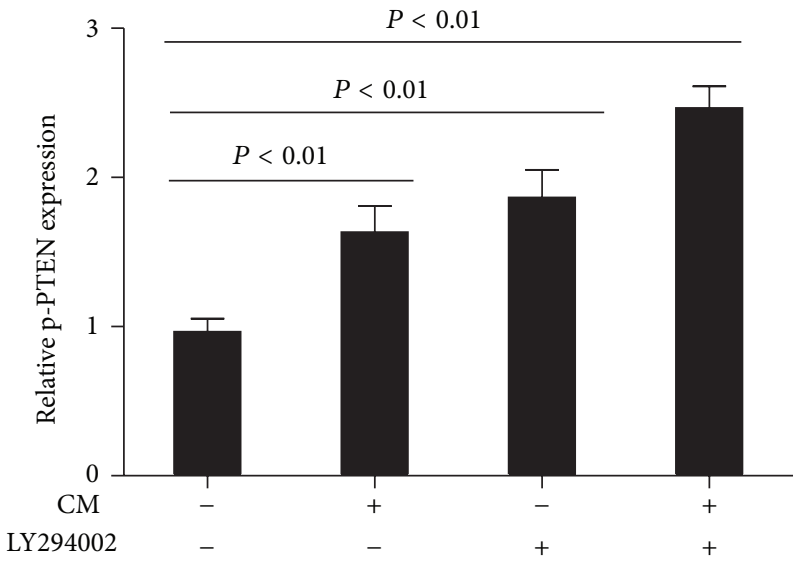

(b)

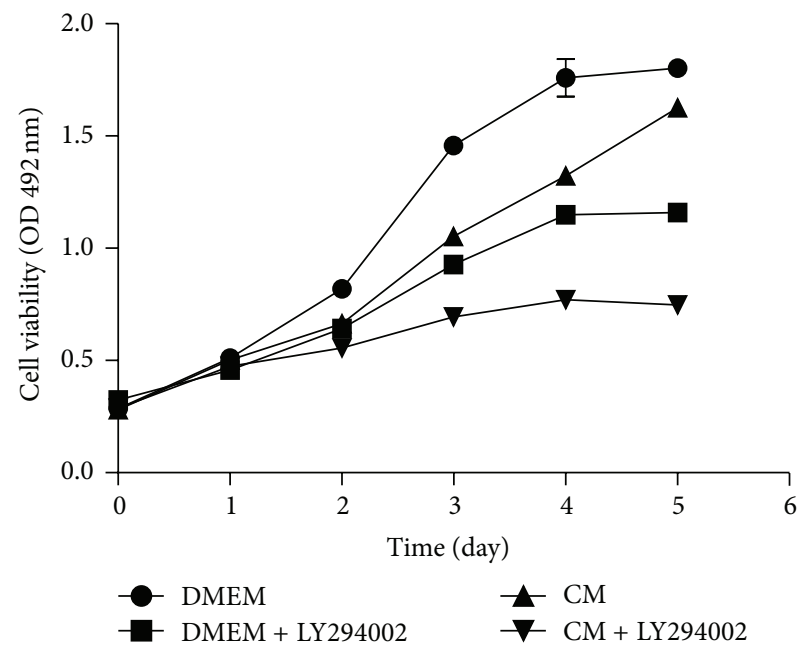

(c)

FIgURE 7: (a) T24 cells was treated with $20 \mu \mathrm{M}$ PI3 kinase inhibitor LY294002 for 60 min and then with ADSC-CM or DMEM for another $24 \mathrm{~h}$. LY294002 decreased the protein levels of Bcl-2 and p-Akt and increased the protein levels of Bax and p-PTEN. Data presented in (b) are the mean \pm SD of three independent experiments $\left({ }^{*} P<0.05\right)$. LY294002 enhances ADSC inhibition of T24 cells growth. T24 cells were treated with ADSC-CM, $20 \mu \mathrm{M}$ LY294002, or both for $24 \mathrm{~h}$. Cell viability was determined by the MTS assay (c). Data shown are the mean \pm SD of three independent experiments.

would like to acknowledge the Institute of Urology, Peking University, for kindly providing EJ and T24 cells. Finally, the authors would like to acknowledge the contribution of Boxing Su, Peng Ge, Zicheng Wang, Yun Cui, Qianling Liu, Mengkui Sun, Lian Zhang, Lu Wang, Sen Li, Bingwei Huang, Yanqing Gong, and Fangrui Ding to this work.

\section{References}

[1] A. Jemal, F. Bray, M. M. Center, J. Ferlay, E. Ward, and D. Forman, "Global cancer statistics," CA Cancer Journal for Clinicians, vol. 61, no. 2, pp. 69-90, 2011.
[2] M. Burger, J. W. F. Catto, G. Dalbagni et al., "Epidemiology and risk factors of urothelial bladder cancer," European Urology, vol. 63, no. 2, pp. 234-241, 2013.

[3] J. S. Colt, M. R. Karagas, M. Schwenn et al., "Occupation and bladder cancer in a population-based case-control study in Northern New England," Occupational and Environmental Medicine, vol. 68, no. 4, pp. 239-249, 2011.

[4] M. F. Pittenger and B. J. Martin, "Mesenchymal stem cells and their potential as cardiac therapeutics," Circulation Research, vol. 95, no. 1, pp. 9-20, 2004.

[5] G. G. Wulf, B. Chapuy, and L. Trümper, "Mesenchymal stem cells from bone marrow. phenotype, aspects of biology, and 
clinical perspectives," Medizinische Klinik, vol. 101, no. 5, pp. 408-413, 2006.

[6] K. Shinagawa, Y. Kitadai, M. Tanaka et al., "Mesenchymal stem cells enhance growth and metastasis of colon cancer," International Journal of Cancer, vol. 127, no. 10, pp. 2323-2333, 2010.

[7] L. Prantl, F. Muehlberg, N. M. Navone et al., "Adipose tissuederived stem cells promote prostate tumor growth," Prostate, vol. 70, no. 15, pp. 1709-1715, 2010.

[8] J. M. Yu, E. S. Jun, Y. C. Bae, and J. S. Jung, "Mesenchymal stem cells derived from human adipose tissues favor tumor cell growth in vivo," Stem Cells and Development, vol. 17, no. 3, pp. 463-473, 2008.

[9] B. Cousin, E. Ravet, S. Poglio et al., "Adult stromal cells derived from human adipose tissue provoke pancreatic cancer cell death both in vitro and in vivo," PLoS ONE, vol. 4, no. 7, Article ID e6278, 2009.

[10] A. Y. Khakoo, S. Pati, S. A. Anderson et al., "Human mesenchymal stem cells exert potent antitumorigenic effects in a model of Kaposi's sarcoma," The Journal of Experimental Medicine, vol. 203, no. 5, pp. 1235-1247, 2006.

[11] P. Secchiero, S. Zorzet, C. Tripodo et al., "Human bone marrow mesenchymal stem cells display anti-cancer activity in SCID mice bearing disseminated non-hodgkin's lymphoma xenografts," PLoS ONE, vol. 5, no. 6, Article ID el1140, 2010.

[12] P. A. Zuk, M. Zhu, H. Mizuno et al., "Multilineage cells from human adipose tissue: implications for cell-based therapies," Tissue Engineering, vol. 7, no. 2, pp. 211-228, 2001.

[13] L. Cui, Y. Shuo, W. Liu, N. Li, W. Zhang, and Y. Cao, "Expanded adipose-derived stem cells suppress mixed lymphocyte reaction by secretion of prostaglandin E2," Tissue Engineering, vol. 13, no. 6, pp. 1185-1195, 2007.

[14] L. Kucerova, V. Altanerova, M. Matuskova, S. Tyciakova, and C. Altaner, "Adipose tissue-derived human mesenchymal stem cells mediated prodrug cancer gene therapy," Cancer Research, vol. 67, no. 13, pp. 6304-6313, 2007.

[15] F. L. Muehlberg, Y.-H. Song, A. Krohn et al., "Tissue-resident stem cells promote breast cancer growth and metastasis," Carcinogenesis, vol. 30, no. 4, pp. 589-597, 2009.

[16] P. A. Zuk, M. Zhu, P. Ashjian et al., "Human adipose tissue is a source of multipotent stem cells," Molecular Biology of the Cell, vol. 13, no. 12, pp. 4279-4295, 2002.

[17] C. Marx, M. D. Silveira, I. Selbach et al., "Acupoint injection of autologous stromal vascular fraction and allogeneic adiposederived stem cells to treat hip dysplasia in dogs," Stem Cells International, vol. 2014, Article ID 391274, 6 pages, 2014.

[18] E. Koellensperger, W. Niesen, J. Kolbenschlag, F. Gramley, G. Germann, and U. Leimer, "Human adipose tissue derived stem cells promote liver regeneration in a rat model of toxic injury," Stem Cells International, vol. 2013, Article ID 534263, 10 pages, 2013.

[19] B. Puissant, C. Barreau, P. Bourin et al., "Immunomodulatory effect of human adipose tissue-derived adult stem cells: comparison with bone marrow mesenchymal stem cells," British Journal of Haematology, vol. 129, no. 1, pp. 118-129, 2005.

[20] P. G. Rychahou, L. N. Jackson, S. R. Silva, S. Rajaraman, and B. M. Evers, "Targeted molecular therapy of the PI3K pathway: therapeutic significance of PI3K subunit targeting in colorectal carcinoma," Annals of Surgery, vol. 243, no. 6, pp. 833-844, 2006.

[21] M. Osaki, M. Oshimura, and H. Ito, "PI3K-Akt pathway: its functions and alterations in human cancer," Apoptosis, vol. 9, no. 6, pp. 667-676, 2004.
[22] L. Kucerova, V. Altanerova, M. Matuskova, S. Tyciakova, and C. Altaner, "Adipose tissue-derived human mesenchymal stem cells mediated prodrug cancer gene therapy," Cancer Research, vol. 67, no. 13, pp. 6304-6313, 2007.

[23] M. Vilalta, I. R. Dégano, J. Bagó et al., "Human adipose tissue-derived mesenchymal stromal cells as vehicles for tumor bystander effect: a model based on bioluminescence imaging," Gene Therapy, vol. 16, no. 4, pp. 547-557, 2009.

[24] M. Lamfers, S. Idema, F. van Milligen et al., "Homing properties of adipose-derived stem cells to intracerebral glioma and the effects of adenovirus infection," Cancer Letters, vol. 274, no. 1, pp. 78-87, 2009.

[25] Y. Zhu, Z. Sun, Q. Han et al., "Human mesenchymal stem cells inhibit cancer cell proliferation by secreting DKK-1," Leukemia, vol. 23, no. 5, pp. 925-933, 2009.

[26] S. L. Etheridge, G. J. Spencer, D. J. Heath, and P. G. Genever, "Expression profiling and functional analysis of Wnt signaling mechanisms in mesenchymal stem cells," Stem Cells, vol. 22, no. 5, pp. 849-860, 2004.

[27] C. A. Gregory, H. Singh, A. S. Perry, and D. J. Prockop, “The Wnt signaling inhibitor Dickkopf-1 is required for reentry into the cell cycle of human adult stem cells from bone marrow," Journal of Biological Chemistry, vol. 278, no. 30, pp. 28067-28078, 2003.

[28] Y. Zhang, C. F. Bellows, and M. G. Kolonin, "Adipose tissuederived progenitor cells and cancer," World Journal of Stem Cells, vol. 2, pp. 103-113, 2010.

[29] P. Charbord and L. Casteilla, "Human mesenchymal stem cell biology," Medecine Sciences, vol. 27, no. 3, pp. 261-267, 2011.

[30] J. Rehman, D. Traktuev, J. Li et al., "Secretion of angiogenic and antiapoptotic factors by human adipose stromal cells," Circulation, vol. 109, no. 10, pp. 1292-1298, 2004.

[31] J. Pan, M. She, Z.-X. Xu, L. Sun, and S.-C. J. Yeung, "Farnesyltransferase inhibitors induce DNA damage via reactive oxygen species in human cancer cells," Cancer Research, vol. 65, no. 9, pp. 3671-3681, 2005.

[32] C. Shi, L. Yu, F. Yang, J. Yan, and H. Zeng, "A novel organoselenium compound induces cell cycle arrest and apoptosis in prostate cancer cell lines," Biochemical and Biophysical Research Communications, vol. 309, no. 3, pp. 578-583, 2003.

[33] S.-T. Lee, M.-H. Lu, L.-H. Chien, T.-F. Wu, L.-C. Huang, and G.-I. Liao, "Suppression of urinary bladder urothelial carcinoma cell by the ethanol extract of pomegranate fruit through cell cycle arrest and apoptosis," BMC Complementary and Alternative Medicine, vol. 13, article 364, 2013.

[34] L. Tang, Y. Zhang, H. E. Jobson et al., "Potent activation of mitochondria-mediated apoptosis and arrest in S and $\mathrm{M}$ phases of cancer cells by a broccoli sprout extract," Molecular Cancer Therapeutics, vol. 5, no. 4, pp. 935-944, 2006.

[35] J. Yao, L. Duan, M. Fan, J. Yuan, and X. Wu, "Overexpression of BLCAP induces $S$ phase arrest and apoptosis independent of p53 and NF- $\kappa$ B in human tongue carcinoma: BLCAP overexpression induces S phase arrest and apoptosis," Molecular and Cellular Biochemistry, vol. 297, no. 1-2, pp. 81-92, 2007.

[36] G. C. Brown and V. Borutaite, "Nitric oxide, cytochrome c and mitochondria," Biochemical Society Symposium, vol. 66, pp. 1725, 1999.

[37] J. Yang, X. Liu, K. Bhalla et al., "Prevention of apoptosis by Bcl2: release of cytochrome c from mitochondria blocked," Science, vol. 275, no. 5303, pp. 1129-1132, 1997.

[38] L. Asnaghi, A. Calastretti, A. Bevilacqua et al., "Bcl-2 phosphorylation and apoptosis activated by damaged microtubules 
require mTOR and are regulated by Akt," Oncogene, vol. 23, no. 34, pp. 5781-5791, 2004.

[39] T. O. Chan, S. E. Rittenhouse, and P. N. Tsichlis, "AKT/PKB and other D3 phosphoinositide-regulated kinases: kinase activation by phosphoinositide-dependent phosphorylation," Annual Review of Biochemistry, vol. 68, pp. 965-1014, 1999.

[40] A. Di Cristofano and P. P. Pandolf, "The multiple roles of PTEN in tumor suppression," Cell, vol. 100, no. 4, pp. 387-390, 2000.

[41] P. A. Steck, M. A. Pershouse, S. A. Jasser et al., "Identification of a candidate tumour suppressor gene, $\mathrm{MMACl}$, at chromosome 10q23.3 that is mutated in multiple advanced cancers," Nature Genetics, vol. 15, no. 4, pp. 356-362, 1997.

[42] A. M. Puzio-Kuter, M. Castillo-Martin, C. W. Kinkade et al., "Inactivation of p53 and Pten promotes invasive bladder cancer," Genes and Development, vol. 23, no. 6, pp. 675-680, 2009. 

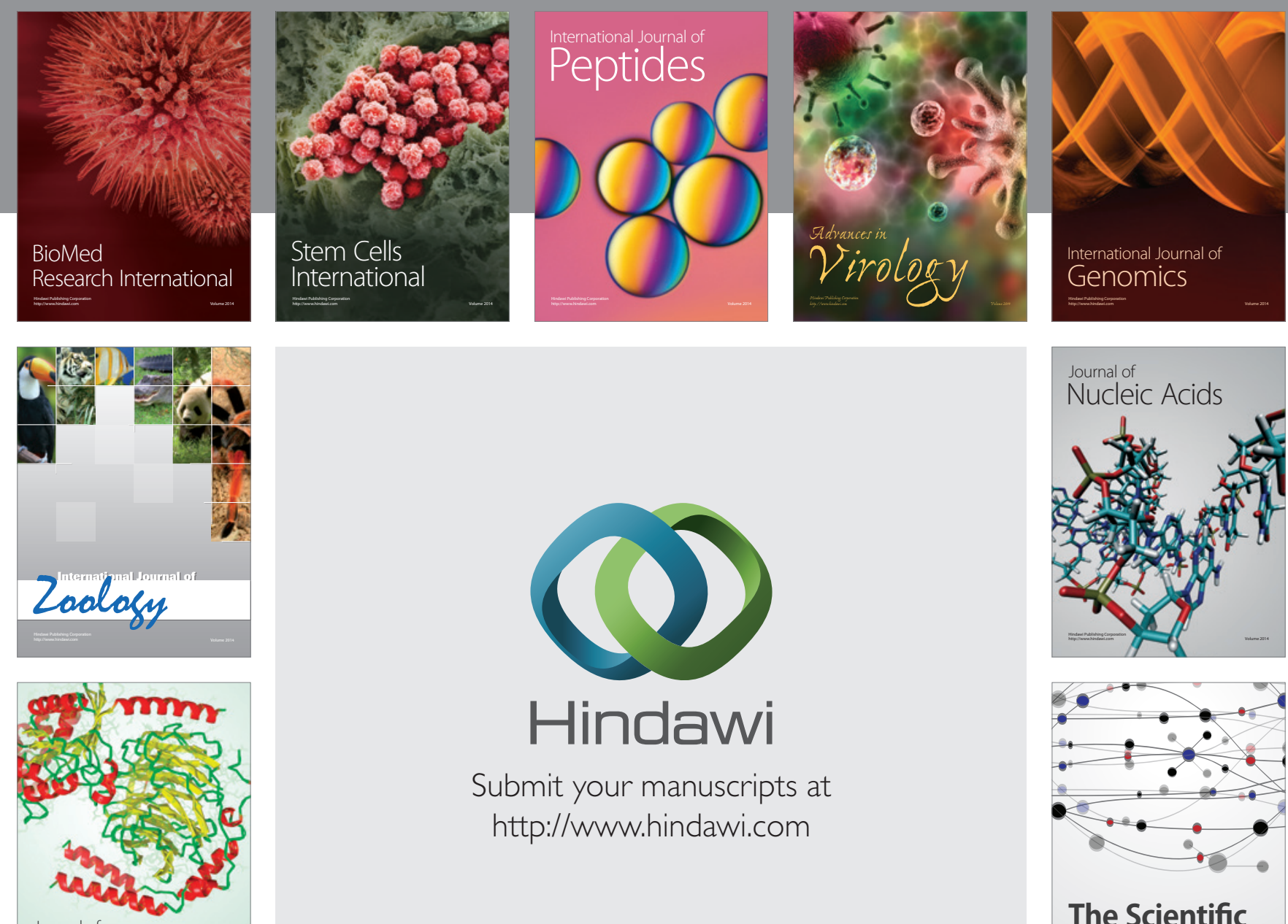

Submit your manuscripts at

http://www.hindawi.com

Journal of
Signal Transduction
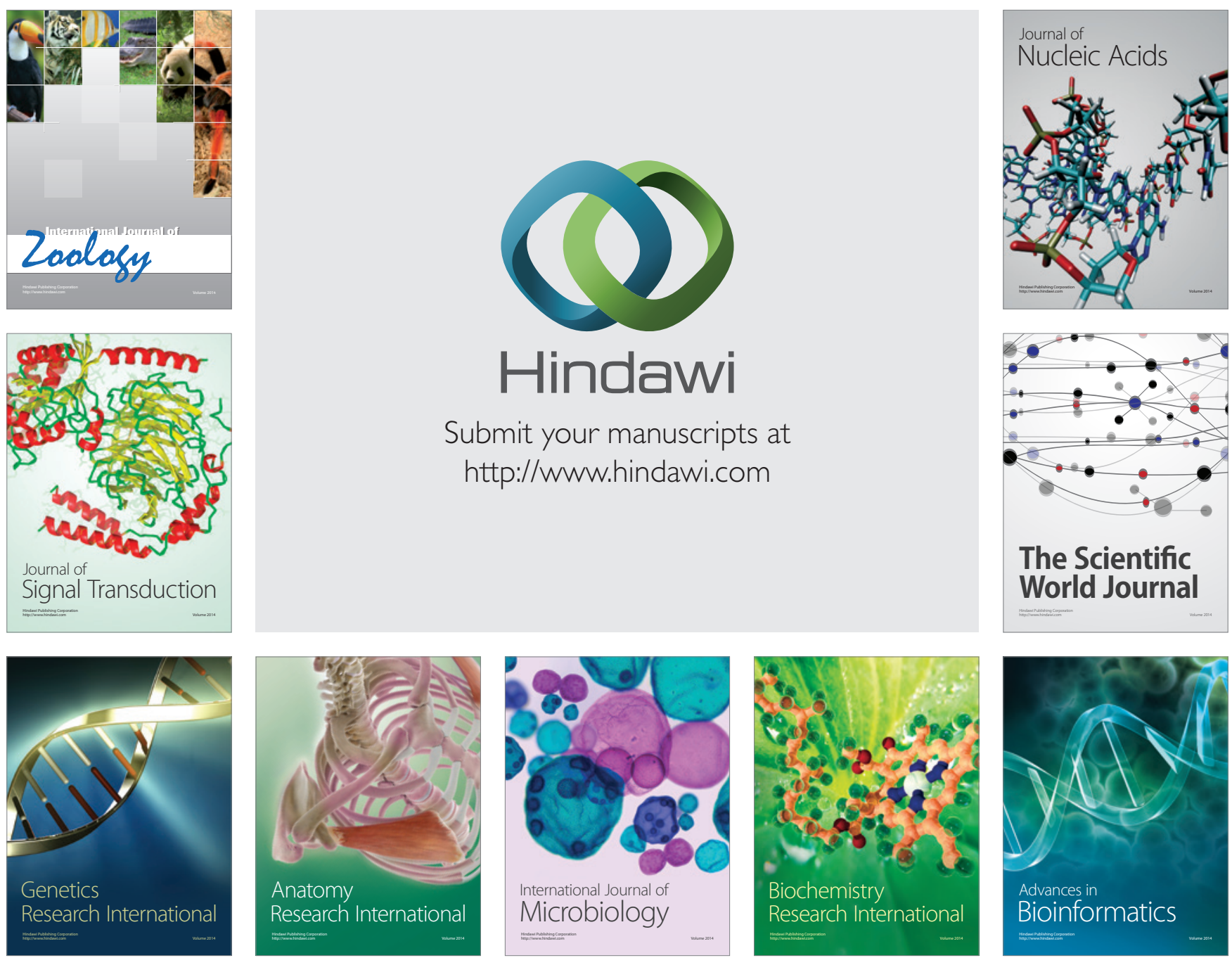

The Scientific World Journal
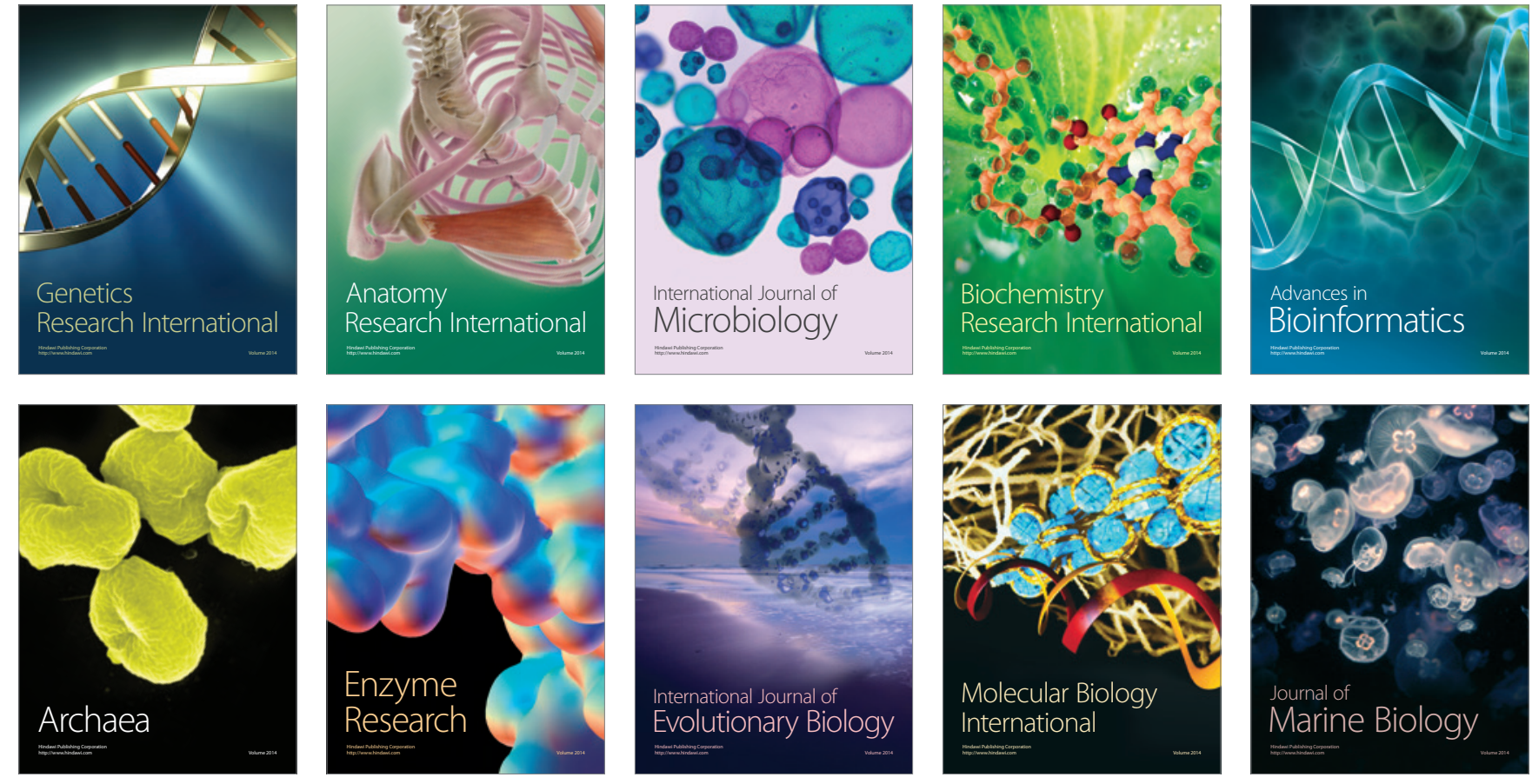